Blobner, F. (Zt. f. Augenh., 1937, 91, 129), Delord, E. (Annales d'Oculistique, 1941, 177, 366), and Tebeyan and Kalfayan (Annales d'Oculistique, 1945, 178, 335), either on the legs or in the retina. We are pleased to see that this thrombophlebitis was also observed by Dr. Prosser Thomas.

Dr. Adamantiades describes this syndrome as the complex syndrome of recurrent iritis with hypopyon, which according to the rules of nomenclature is the name and term accepted by Grsek medical literature. May we add that this syndrome is compared to the disease known as "periodic ophthalmia ("moonblindness ') of horses" according to the same author. I should like to add that Dr. Thomas's contribution to the subject is much welcomed in Greek medical circles in Athens.-I am, etc.,

Athens.

NiKos LoRANDOS.

\section{Vaginal Operations}

SIR,-May I be allowed to reply to Dr. T. F. Redman's letter (May 31, p. 784), in which he criticizes my statement: "carcinoma of the vaginal portion of the cervix only occurs in women who have been pregnant." Perhaps I did not make myself clear enough in that, in this statement, I referred only to that type of carcinoma which arises from epithelium similar to that which lines the vagina-namely, squamous-celled carcinoma. I quite agree that columnar-celled carcinoma occurs quite frequently in the cervical canal in nulliparous women This type of carcinoma, although occurring in the vaginal portion of the cervix if this be judged on a strict anatomical basis, should, I think, be considered on a pathological basisnamely, as a continuation of the uterine cavity, although of course the type of columnar-celled carcinoma is modified in the endocervical portion of the uterus.

I have investigated the 108 Mayo Clinic cases of stump carcinomata referred to by Dr. Redman, and a considerable proportion of these would seem to be cases of columnar-celled carcinoma, and the incidence of these cases would not be affected by previous pregnancy. Again, in this series I cannot find any reference to the question of a previous abortion. This point I consider important, since I should like to make it clear that when I mentioned pregnancy I also included those cases with a previous history of abortion. The table of Dr. Hurdon in which she compares the incidence of carcinoma in single and in married women is of little value, since pregnancy and abortion are not confined entirely to married women.

My original statement was based upon the teaching of $\mathrm{Mr}$. T. G. Stevens, and in my five years as his registrar I had ample opportunity to confirm the aetiological relationship which occurs between the incidence of squamous-celled carcinoma of the cervix and pregnancy or abortion. Naturally I am aware that this type of investigation must of necessity be unsatisfactory, since one has to rely entirely upon the truthfulness of one's patient. If, however, Dr. Redman is prepared to concede that squamous-celled carcinoma of the cervix occurs more frequently in women who have been pregnant than in those who have not been pregnant, then my original object, which was to strongly support Mr. Wilfred Shaw in his advocacy of vaginal hysterectomy in certain types of prolapse, will have been attained.-I am, etc.,

Southport.

JoHN H. HanNaN.

\section{Printed Clinical Lectures}

SIR,-I read with considerable interest Prof. L. J. Witts's review (May 3, p. 602) and Dr. Edwin Bramwell's letter (May 24 , p. 741) on this subject, and would like to support Dr. Bramwell. I feel there is a distinct place in academic medicine for the clinical lecture from the verbal and written point of view. A lecture centred round a patient is invested with a definite personal touch, and the subsequent committing of it to print may be of benefit to those who were unable to be present. I have derived much pleasure and profit in reading over my notebook of notes taken while a clinical student. These represent a very fascinating medical and surgical anthology in diverse topics of fundamental clinical importance.

Doctors feel that to-day there is a certain deterioration in the art of lecturing, and it should be the rule that only those members of an academic staff of a hospital should lecture who are gifted in that manner. A man may be a born clinician but not necessarily a teacher as well. It is inspiring to pick up a volume of clinical lectures by such a giant as Sir James Paget, who, we are told, would rehearse his lectures walking up and down in the open air, to realize the profundity of clinical as well as classical knowledge that he possessed. An apt literary quotation may do much to tone up a discourse on a dull topic, although, well taught, medicine never should be dull. As a student at Bart's I recall many an issue of the hospital journal contained a printed clinical lecture delivered by one of the chiefs of the hospital. I was always grateful to the editor for printing it and so making it available to a far wider audience.-I am, etc.,

Sutton, Surrey.

J. B. Gurney SMith.

\section{General Knowledge and General Practice}

SIR,-The subject of medical education is one of perpetual joy for committees and correspondents. Representatives of all branches of medical science-the paediatricians, the physiologists, the psychiatrists, the protagonists of social medicine, and the others - continually advocate extending the curriculum (with especial regard to their own subject) so as to make the student a more capable medical practitioner. Neither they nor anyone else seem to consider making the student a better citizen, humanist, or scientist. While they stress the technique of the profession they forget the "broad cultural background."

This letter is a plea for recognition that a "duly qualified medical practitioner" able to treat disease is not necessarily a "doctor" fully competent to take an active part in public life and enlightened circles. For that he needs a fair amount of extra-curricular non-medical knowledge. He must know not only the divisions of the peroneal artery but also the divisions of the Liberal Party, not only the development of the normoblast but also the development of uranium 235, not only the difference between Arnold Pick's disease and Friedel Pick's disease but also the difference beween George Moore and Henry Moore.

Since matriculation many of us have had no formal contact with politics and the humanities, economics, and the arts, and only the most far-sighted of our teachers bothered to remind us of their existence. The London medical schools (in particular) seem nowadays almost to be technical colleges for the study of anatomy, cardiology, and all the other "subjects." Perhaps it is still possible for an enlightened dean to sponsor a series of lectures on the economics of foreign policy, or a courageous university to introduce into the third M.B. a question on existentialism. It is the examining bodies who, by not insisting on a reasonable standard of general knowledge, allow some number of medical practitioners to be merely "clinical technicians." To raise this standard it is up to these bodies to include a compulsory general paper in the final examination. The practice in many countries abroad (with what results I do not know) of having medical students take an arts degree first is, I believe, considered impractical here for reasons of time, expense, and shortage of doctors.-I am, etc.,

London. N.W.4

D. N. BARON.

\section{Remuneration in N.H.S.}

SIR,-It may take many months for a doctor's capitation list of new Health Service insured persons to approximate in numbers to his present adult private patients. There will therefore be a considerable time-lag during which every general practitioner entering the new Service will find his income depleted, yet he will be working harder than ever with so many potential patients awaiting his "free" services-patients who do not appear on his list and for whom he will receive no payment until they do so appear-usually when they are in need of treatment, which may be months or even years after the appointed day.

I write to point out that steps should be taken now to ensure that future insurable persons will in fact apply for inclusion on the list of the doctor of their own choice on the given day, not only by arranging for publicity in the daily Press but by the distribution of application forms to post offices, insurance agencies, and doctors, and that some penalty might be devised for those who do not join within three months-for instance, 